\title{
Magneto Hydrodynamics Free Convection in a Rectangular Enclosure with Three Square Heated Block
}

\author{
Md. Raihanul Haque', Md. Abdul Alim², Md. Mahmud Alam , Md. Shahidul Alam ${ }^{1}$, * \\ ${ }^{1}$ Department of Mathematics, Dhaka University of Engineering \& Technology, Gazipur, Bangladesh \\ ${ }^{2}$ Department of Mathematics, Bangladesh University of Engineering and Technology, Dhaka, Bangladesh
}

Email address:

mistraihan81@gmail.com (Md. R. Haque), alamdr.mahmud@yahoo.com (Md. M. Alam), a0alim@gmail.com (Md. A. Alim), shdlalam $a$ gmail.com (Md. S. Alam)

${ }^{*}$ Corresponding author

\section{To cite this article:}

Md. Raihanul Haque, Md. Abdul Alim, Md. Mahmud Alam, Md. Shahidul Alam. Magneto Hydrodynamics Free Convection in a Rectangular Enclosure with Three Square Heated Block. International Journal of Theoretical and Applied Mathematics. Vol. 5, No. 6, 2019 , pp. 74-82. doi: $10.11648 /$ j.ijtam.20190506.11

Received: October 14, 2019; Accepted: November 9, 2019; Published: November 21, 2019

\begin{abstract}
In the present study the effect of natural convection in a rectangular cavity with three square shape heated block is focused in this numerical is studied. The horizontal bottom wall and three square blocks are temperature $T_{h}$ while the left and right vertical walls and horizontal top wall are temperature $T_{c}$ with $T_{h}>T_{c}$. The governing equations along with appropriate boundary conditions for the present problem are first transformed into a non-dimensional form and the resulting non linear system of partial differential equations are then solved numerically using Galerkin's finite element method. Parametric studies of the fluid flow and heat transfer in the enclosure are performed for magnetic parameter Hartmann number Ha, Prandtl number $\operatorname{Pr}$ and Rayleigh number $R a$. The streamlines, isotherms and average Nusselt number at the hot wall and average temperature of the fluid in the enclosure are presented for the parameters. The numerical results indicate that the Hartmann number and Rayleigh number have strong influence on the streamlines and isotherms. On the other hand Prandtl has little effect on the stream line and isotherm plots. Finally, the mentioned parameters have significant effect on average Nusselt number at the hot wall and average temperature of the fluid in the cavity.
\end{abstract}

Keywords: Finite Element Method, Numerical Simulation, Natural Convection and Square Block, Rectangular Cavity

\section{Introduction}

Natural Over the last several decades, mixed convection heat transfer has received considerable attention by researchers and scholars. Natural and Mixed convection has many engineering application such as cooling of electronic components, energy conservation, electronic packaging, printing and printing process, material processing etc. Moallemi and Jang [1] studied numerically mixed convection flow in a bottom heated square lid driven enclosure andanalyzed the effect of Prandtl number on the flow and heat transfer process. They obtained that the effects of buoyancy are more effective for higher values of Prandtl number. Shahidul et al. [2] conducted a numerical study on mixed magneto convection in a lid driven square enclosure with a sinusoidal vertical wall and joule heating. He examined that the heat transfer and the flow characteristics inside the enclosure depends strongly upon the strength of magnetic field. Malleswaran and Sivasankaran [3] performed a numerical simulation on MHD mixed convection in a lid driven cavity with corner heaters. They observed that the overall heat transfer is better at forced convection mode than that of free convection mode. Ahmed F. Khudheyer [4] investigated the MHD mixed convection in a double lid driven differentially heated trapezoidal cavity. They conclude that in an absence of magnetic field the maximum heat transfer occurs at lower inclination angle. Rahman [5] conducted numerical study on the conjugate effect of joule heating and magneto hydrodynamic mixed convection in an obstructed lid driven square cavity. The found that the average Nusselt number at the Heated surface increased due to the increasing of joule heating number. Moallemi and Jang [6] reported on the effect of $\operatorname{Pr}$ number on laminar mixed 
convection heat transfer in a lid driven cavity. They yields that the effects of natural convection are always assisting the force convection. Hakan and Dagtekin [7] analyzed mixed convection in two sided lid driven differentially heated square cavity. They found that influence of moving of moving wall on the heat transfer is the same when move in opposite direction. Mahmud and Fraser [8] presented quantitative results of magneto dynamic free convection and entropy generation in a square porous cavity. They observed that entropy generation rate is decreased in magnitude as the magnetic force is introduced and strengthened. Sahaet al. [9] studied mixed convection in a lid driven cavity with internal heat source. They observed that the heat transfer from the moving top wall is always found to be higher than the stationary bottom wall. Jani et al. [10] developed magneto hydrodynamic free convection in a square cavity heated from below and cooled from other walls. Alam et al. [11] established finite element analysis of MHD natural convection in a rectangular cavity and partially heated wall. They found that heat transfer mechanism, temperature distribution and the flow characteristics inside the cavity depended strongly upon both the strength of the magnetic field and the Rayleigh number. Alam et al. [12] formulated numerical simulation of natural convection in a rectangular cavity with triangles of different orientation in presence of magnetic field. Where we found the orientation of triangular heated body has an effect on the flow and temperature fields. Alam et al. [13] investigated numerical simulation of natural convection in a rectangular cavity with corner heater in presence of magnetic field. Alam et al. [14] analyzed effect of Prandtl number on magneto-convection in a lid driven square cavity with a sinusoidal vertical wall. They concluded that the Prandtl number thermal diffusivity dominates, this means that conduction dominates over convection. Alam et al. [15] performed mixed magneto convection in a lid driven square enclosure with a sinusoidal vertical wall and joule heating. Halim Bhuiyanet. al [16] developed the effect of Hartmann Number on Free Convective Flow in a Square Cavity with Different Positions of Heated Square Block. Abraham and Varghese [17] studied mixed convection in a differentially heated square cavity with moving lids. They found that the buoyancy force dominates the flow for higher Richardson number and inertia force dominate the flow for Richardson number (Ri) less than one. Kishireet al. [18] discussed the effect of heat transfer and viscous dissipation on MHD free convection flow past an exponentially accelerate vertical plate with variable temperature they found that the velocity and temperature increases with the increases of Eckert number. Sadrul Islam et al. [19] carried out to study the performance of mixed convection in a rectangular enclosure where four different placement configurations of the inlet and outlet openings were considered. The results indicate that the average Nusselt number and the dimensionless surface temperature on the heat source strongly depend upon the positioning of the inlet and outlet. Raji and Hasnaoui [20] studied mixed convection heat transfer in a ventilated cavity subject to a uniform heat flux.
Caronna et al. [21] discussed the natural convection in shallow and tall cavities with the four walls differentially heated. It has been found that the heat transfer performance of the cavity increases with increasing the Rayleigh number and the aspect ratio. Ghalambazet al. [22] examined the influence of the viscous dissipation and radiation effects on the natural convection heat transfer in a square cavity filled with porous media saturated with a nanofluid. The result showed that the Nusselt numbers at the hot and cold walls are not equal due to the presence of viscous dissipation effects. Mehmet and Eliif Buyuk [23] considered natural convection flow under a magnetic field in an inclined rectangle enclosure heated and cooled on adjacent walls. They found that circulation inside the enclosure and therefore the convection become stronger as the Grashof number increases while the magnetic field suppresser the convection flow and the heat transfer rate. A numerical study of laminar natural convective heat transfer inside a closed cavity with different aspect ratio was studied by Paritosh and Sangita [24]. The proposed result is that as Rayleigh number increases the enhanced natural convection become dominant and the additional friction is negligible, leading to that the maximum stream functions at lower aspect ratios are apparently greater than those at higher convection flows in a square cavity with non-uniform heating wall(s). Sinusoidal type of variations in heat with $\mathrm{Ra}=10^{5}$. Natural convection studies in enclosures with vents and internal heat source at high Rayleigh number $\left(\mathrm{Ra}>10^{6}\right)$ has been analyzed by Gowrishankar [25]. They observed that with increase in Ra, flow becomes more fluctuating and moves towards chaotic regime. Roy and Basak [26] studied that the finite element analysis of natural convection flows in a square cavity with non-uniform heating wall(s). Sinusoidal type of variations in heat with $\mathrm{Ra}=10^{5}$. Khalil et al. [27] performed an experimental investigation flow in a lid driven enclosure field with a saturated porous medium. They found significant suppression of the convective currents was obtained by the presence of a porous media. C. Taylor, and V. Hood,[28] "A numerical solution of the Navier-Stokes equations using finite element technique", Comput.

The above literature review advised the authors,' attention has been given to the problem of natural and mixed convection for different types of geometry like rectangular, square and trapezoidal etc. But no investigation has been done yet on magneto hydrodynamics free convection in a rectangular enclosure with three square heated blocks.

\section{Physical Model}

The present problem is a two-dimensional square cavity with a side length L. The physical system considered in the present study is displayed in Figure 1. The top and bottom walls are taken adiabatic and impermeable while the vertical walls are maintained at uniform but different temperatures such that the right wall is assigned to temperature $T_{c}$ while the left wall is subjected to temperature $T_{h}$ under all circumstances $T_{h}>T_{c}$ condition is maintained. Furthermore, 
the right wall is assumed to slide frombottom to top at a constant speed $\mathrm{U}_{0}$ and left wall is sinusoidalwavy pattern $\mathrm{A}$ magnetic field of strength $\mathrm{B}_{0}$ is acting in a transversedirection normal to the side walls.

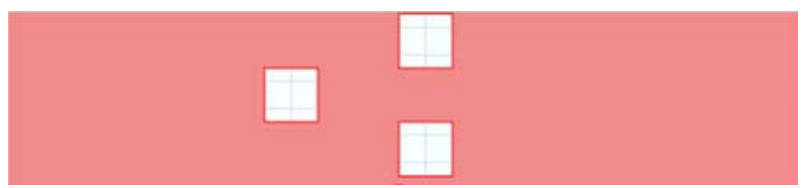

Figure 1. Schematic diagram of the physical system.

\section{Mathematical Formulations}

Under these assumptions the equations of Continuity, momentum and energy are:

Continuity Equation:

$$
\frac{\partial u}{\partial \bar{x}}+\frac{\partial v}{\partial \bar{y}}=0
$$

Momentum Equations

$$
\begin{gathered}
\rho\left(u \frac{\partial u}{\partial x}+v \frac{\partial u}{\partial y}\right)=-\frac{\partial p}{\partial x}+\mu\left(\frac{\partial^{2} u}{\partial x^{2}}+\frac{\partial^{2} u}{\partial y^{2}}\right) \\
\rho\left(u \frac{\partial v}{\partial x}+v \frac{\partial v}{\partial y}\right)=-\frac{\partial p}{\partial x}+\mu\left(\frac{\partial^{2} v}{\partial x^{2}}+\frac{\partial^{2} v}{\partial y^{2}}\right)+\rho g \beta(T-T c)-\sigma B_{0} v
\end{gathered}
$$

Energy equations

$$
u \frac{\partial T}{\partial x}+v \frac{\partial T}{\partial y}=\alpha\left(\frac{\partial^{2} T}{\partial x^{2}}+\frac{\partial^{2} T}{\partial y^{2}}\right)
$$

where $\mathrm{x}$ and $\mathrm{y}$ are the distances measured along the horizontal and vertical directions respectively; $u$ and $v$ arethe velocity components in the $\mathrm{x}$ and $\mathrm{y}$ directions respectively; $\mathrm{T}$ denotes the fluid temperature and $T_{c}$ denotes the reference temperature for which buoyant force vanishes, $p$ is the pressure and $\rho$ is the fluid density, $g$ is the gravitational acceleration $\beta$ is the volumetric coefficient of thermal expansion, $C_{p}$ is the specific heat at constant pressure. The above equations will be making dimensionless, we introduce the following non-dimensional variables are as follows:

$$
\begin{gathered}
X=\frac{x}{H}, Y=\frac{y}{H}, U=\frac{u H}{v}, V=\frac{v H}{v} \\
P=\frac{p H^{2}}{\rho v^{2}}, \quad \theta=\frac{T-T_{c}}{T_{h}-T_{c}}
\end{gathered}
$$

Where $v\left(=\frac{\mu}{\rho}\right)$ the reference kinematic viscosity and $\theta$ isthe non-dimensional temperature. After substitution of dimensionless variables (5) into equations (1)-(4) the nondimensional governing equations for steady two-dimensional free convection flow in the rectangular cavity are as follows:
Continuity Equation:

$$
\frac{\partial U}{\partial X}+\frac{\partial V}{\partial Y}=0
$$

Momentum Equations

$$
U \frac{\partial U}{\partial X}+V \frac{\partial U}{\partial Y}=-\frac{\partial P}{\partial X}+\operatorname{Pr}\left(\frac{\partial^{2} U}{\partial X^{2}}+\frac{\partial^{2} U}{\partial Y^{2}}\right)
$$

$U \frac{\partial V}{\partial X}+V \frac{\partial V}{\partial Y}=-\frac{\partial P}{\partial Y}+\operatorname{Pr}\left(\frac{\partial^{2} V}{\partial X^{2}}+\frac{\partial^{2} V}{\partial Y^{2}}\right)+R a \operatorname{Pr} \theta-H a^{2} \operatorname{Pr} V$

Energy Equations

$$
U \frac{\partial \theta}{\partial X}+V \frac{\partial \theta}{\partial Y}=\left(\frac{\partial^{2} \theta}{\partial X^{2}}+\frac{\partial^{2} \theta}{\partial Y^{2}}\right)
$$

In the above equations $\mathrm{Ra}$ is the Rayleigh number, $\mathrm{Pr}$ is the number and the heat generation parameter defined by the following relations

$$
R a=\frac{\beta\left(T_{h}-T_{c}\right) H^{3}}{\alpha v}, \operatorname{Pr}=\frac{v}{\alpha}, \mathrm{Ha}=\mathrm{B}_{0} H \sqrt{\frac{\sigma}{\rho v}}
$$

The non-dimensional boundary conditions under consideration can be written as:

$$
U=0, V=0, \theta=1
$$

at the left and right vertical walls; $U=0, V=1, \theta=1$ at the bottom wall and square obstacle and $U=0, V=1$ and $\frac{\partial \theta}{\partial y}=1$ at the top wall. Where $\mathrm{X}$ and $\mathrm{Y}$ are dimensionless coordinates varying along horizontal and vertical directions, respectively; $\mathrm{U}$ and $\mathrm{V}$ are dimensionless velocity components in $\mathrm{X}$ and $\mathrm{Y}$ directions, respectively; $\theta$ is the dimensionless temperature where $\mathrm{N}$ is the non-dimensional distances either along $\mathrm{X}$ or $\mathrm{Y}$ direction acting normal to the surface. The local Nusselt number at the heated surface of the cavity which is defined by the following expression

$$
N u_{l}=N u_{r}=N u_{b}=N u_{s}=-\frac{\partial \theta}{\partial N}
$$

where $\mathrm{n}$ denotes the normal direction on a plane.

\section{Numerical Analysis}

The numerical procedure used to solve the governing equations for the present work is based on the Galerkin weighted residual method of finite-element formulation. The non-linear parametric solution method is chosen to solve the governing equations. This approach will result in substantially fast convergence assurance. A non-uniform triangular mesh arrangement is implemented in the present 
investigation to capture the rapid changes in the dependent variables. The velocity and thermal energy equations (1)-(4) result in a set of non-linear coupled equations for which an iterative scheme is adopted. In this method, the continuum domain is divided into a set of non-overlapping regions called elements. Six node triangular elements with quadratic interpolation functions for velocity as well as temperature and linear interpolation functions for pressure are utilized to discretize the physical domain. Moreover, interpolation functions in terms of local normalized element coordinates are employed to approximate the dependent variables within each element.

All six nodes are associated with velocities as well as temperature; only the corner nodes are associated with pressure. This means that a lower order polynomial is chosen for pressure and which is satisfied through continuity equation. These residuals are reduced to zero in a weighted sense over each element volume using the Galerkin method. Details of the method are available in Taylor and Hood (1973).

\section{Grid Independent Test}

In order to obtain grid independent solution, a grid refinement study is performed for a rectangular cavity with $P r=0.71$, and $R a=10^{5}$. Figure 2 shows the convergence of the average Nusselt number, at the heated surface with grid refinement. It is observed that grid independence is achieved with 23422elements where there is insignificant change in $\mathrm{Nu}$ with further increase of mesh elements. Eight different non-uniform grids with the following number of nodes and elements were considered for the grid refinement tests: 512 nodes, 724 elements; 881nodes, 1318 elements; 1012 nodes, 2002 elements; 1630 nodes, 3637 elements; 2621 nodes, 5380 elements; 4132 nodes, 9326 elements; 11779 nodes, 23422 elements; 24931 nodes, 58854 elements.. From these values, 11779 nodes 23422 elements can be chosen throughout the simulation to optimize the relation between the accuracy required.

Table 1. Grid Sensitivity Check at $P r=0.7, \phi=0, H a=50$ and $R a=10^{5}$.

\begin{tabular}{|c|c|c|c|c|c|c|c|c|}
\hline Nodes & 5120 & 881 & 1012 & 1630 & 2621 & 4132 & 11779 & 24931 \\
\hline Elements & 724 & 1318 & 2002 & 3637 & 5380 & 9326 & 23422 & 58854 \\
\hline$N u$ & 5.80464 & 5.31219 & 5.43428 & 5.59152 & 5.7230 & 5.80464 & 6.10867 & 6.15699 \\
\hline
\end{tabular}

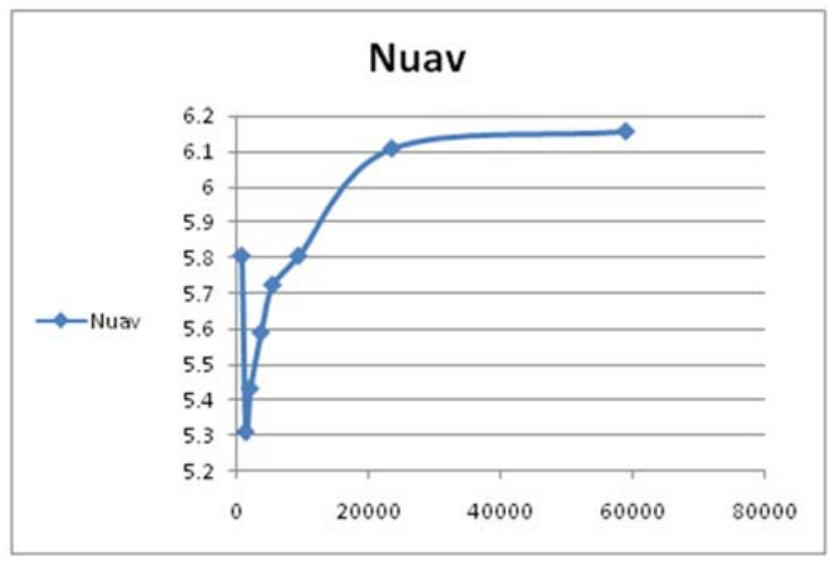

Element

Figure 2. Graph of average Nusselt Number.

\section{Validation}

Figure 3 represents the comparison of present result with Jani et al. [10]. Effect of the Hartman number on vertical component of the velocity along the horizontal midline of the cavity at $\mathrm{Ra}=10^{6}$ is shown in Figure 3. Comparison of velocity profile have been shown for $\mathrm{Ha}=0,50$ and100. As can be seen from the figure with increase in Hartman number motivates the flow velocity to decreases. A very slow fluid velocity occurs at $\mathrm{Ha}=100$. It is found that free convection heat transfer decreases with increase in fluid velocity via increasing the Hartman number. The results of present works and Jani et al. [10] are found is good agreement.

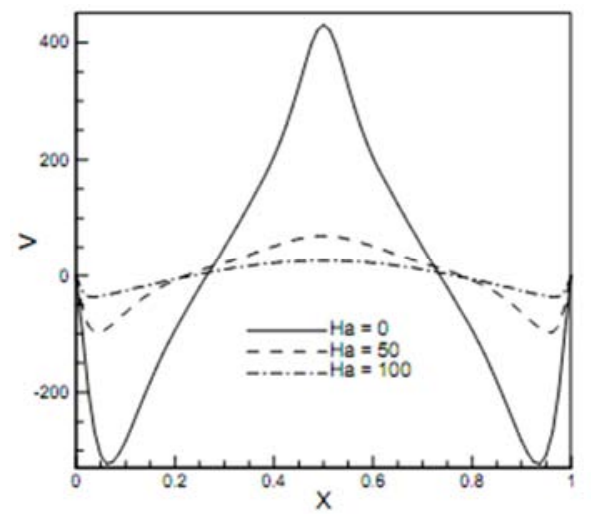

Jani et al. [10].

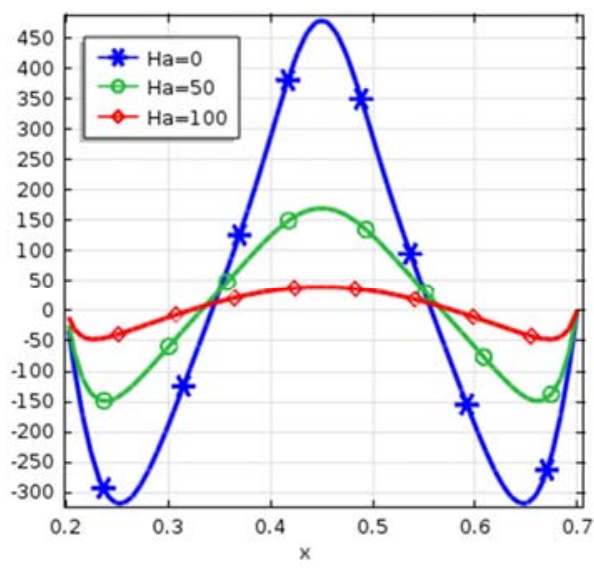

Present Work

Figure 3. Comparison of present result with Jani et al. [10]. 


\section{Results and Discussions}

A numerical study has been carried out for a wide range of Hartmann number $(\mathrm{Ha}=0.50)$ and Rayleigh number $\left(\mathrm{Ra}=10^{3}\right.$, $10^{6}$ ) on natural convection in a rectangular cavity with three square shaped heated block. The results are presented in terms of streamlines, isotherms velocity profile, temperature distribution and local Nusselt number inside the cavity. Velocity component and temperature distribution taken along the vertical midline of the cavity for $\operatorname{Pr}=0.71$. Figure 4, Figure 5, Figure 6, and Figure 7 represent the streamlines for $\mathrm{Ra}=10^{3} 10^{4}, 10^{5}$ and $10^{6}$ respectively It is found insignificant change in the results from Figure 4 for different values of Hartmann number and $\mathrm{Ra}=10^{3}$. Figure 5, Figure 6, and Figure 7 had shown significant changes in streamlines, for gradually higher values of Rayleigh number. Vortices had been created at the left part of enclosure all most all cases. Streamlines were absent for $\mathrm{Ha}=30$ and $\mathrm{Ra}=10^{6}$ in Figure 7. The fluid near the bottom(hot) wall has lower density so it moves upward while the relatively heavy fluid near the left(cold) wall and this fluid if heated up. Thus the fluid motion completes the circulation. A pair of counter rotating eddies are formed in the left and right half of the cavity for all Rayleigh number considered except $\mathrm{Ra}=1000$. For magnetic field $(\mathrm{Ha}=0,10,30,50)$ the elliptic shaped eddies are in the center of the left part of vertical centerline and middle of the right wall. It means that increasing of magnetic field reduced the flow velocity. Meanwhile there is small change of circulation of right side of the cavity. For higher Rayleigh number the flow strength increases are shown in Figure 6 and Figure 7, for $\mathrm{Ha}=30$ and 50. From the streamlines in figure 7 it is found that with the increasing of Hartmann number that means the increase of strength of magnetic field the eyes of the vortices slightly changes and decrease in the flow velocity and numbers of mainstream flows are increased.

The corresponding effects on the temperature field are shown in Figure 8, Figure 9, and Figure 10, and Figure 11. The isotherms seem to be symmetrical and uniform. But with the increase of $\mathrm{Ra}$ number isotherms get a nonuniform structure. The isotherms are almost parallel tothe top wall and left vertical wall for higher value of Ha and $\mathrm{Ra}$, representing that most of the heat transfer process is carried out by conduction. Moreover some deviations in the conduction dominated isothermal lines are initiated near the right vertical wall for $\mathrm{Ra}=10^{6}$. Variations of the vertical velocity component along the vertical centerline of the cavity with the Rayleigh number and for $\mathrm{Ha}=0$ are shown in Figure 12. It can be seen from the Figure that the velocity increases with the increase of Rayleigh number. Effect of the Hartmann number on vertical component of the velocity along the vertical midline of the cavity at $\mathrm{Ra}=10^{6}$ is shown in Figure 13. As we can see from the Figure 13 the absolute value of velocity can be found in absence of magnetic field $(\mathrm{Ha}=0)$. Variation of the Local Nusslet number alone the hot bottom wall with the Rayleigh number in the absence of the magnetic field
$(\mathrm{Ha}=0)$ are shown in Figure 14. The local Nusslet is symmetrical with respect to the vertical midline of the cavity. It can be seen from the figure that the local number increases with the increases with the Rayleigh number. In the middle of the bottom wall the local Nusselt number is equals to zero and does not change significantly with the increase in Rayleigh number. Variation of the local Nusslet number along the hot wall of the cavity with the Hartmann number at $\mathrm{Ra}=10^{6}$ are shown in Figure 15 . We observed from the figure in whole portion of the cavity the local Nusslet number decreases with the increases in the Hartmann number.

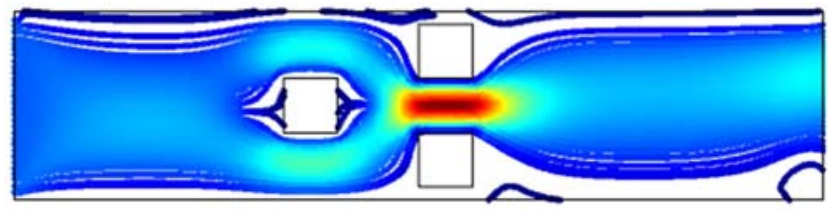

$H a=0$.

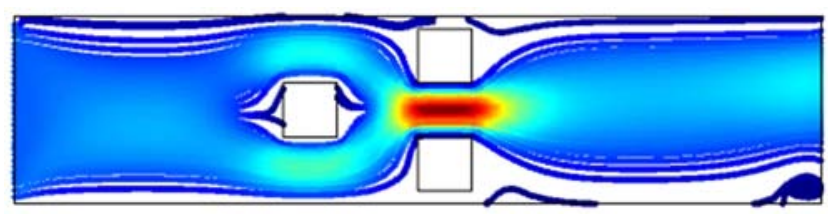

$H a=10$.

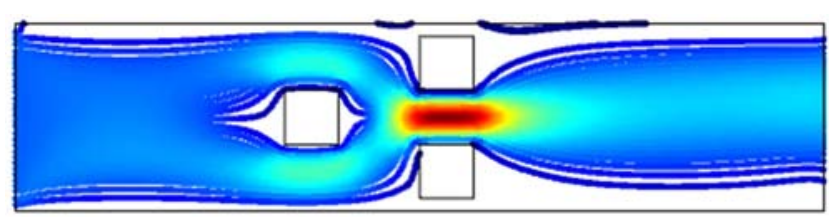

$H a=30$

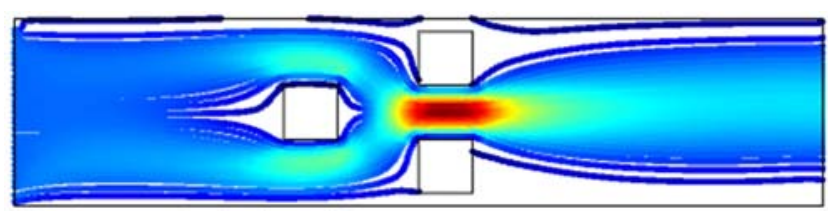

$H a=50$.

Figure 4. Streamlines for $\mathrm{Ra}=10^{3}, \mathrm{Pr}=0.71 \mathrm{Ha}=0$; $\mathrm{Ha}=10 ; \mathrm{Ha}=30 ; \mathrm{Ha}=50$.

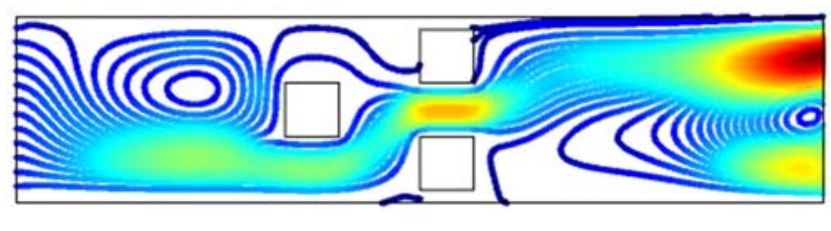

$H a=0$.

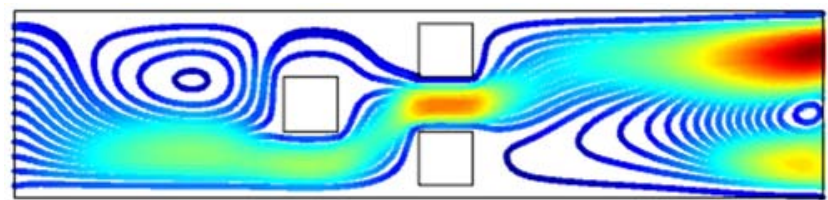

$H a=10$. 


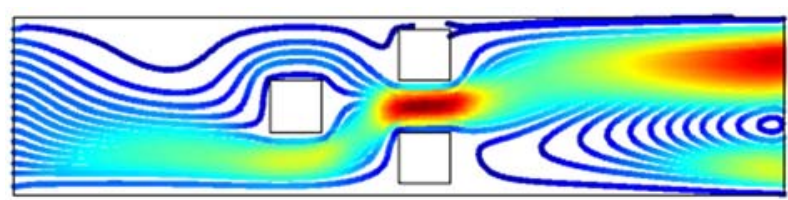

$H a=30$.

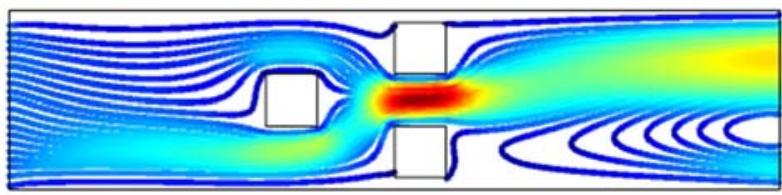

$H a=50$.

Figure 5. Streamlines for $\mathrm{Ra}=10^{4}, \mathrm{Pr}=0.71 \mathrm{Ha}=0 ; \mathrm{Ha}=10 ; \mathrm{Ha}=30 ; \mathrm{Ha}=50$.

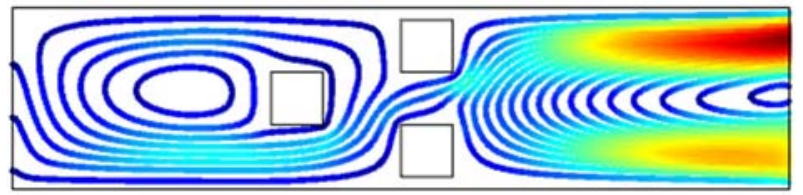

$H a=0$.

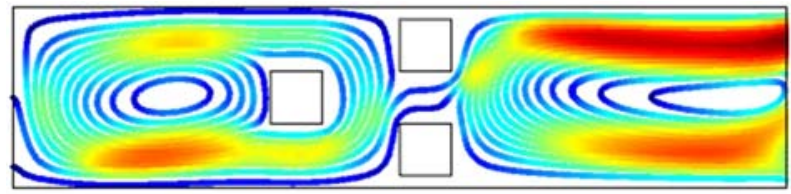

$H a=10$

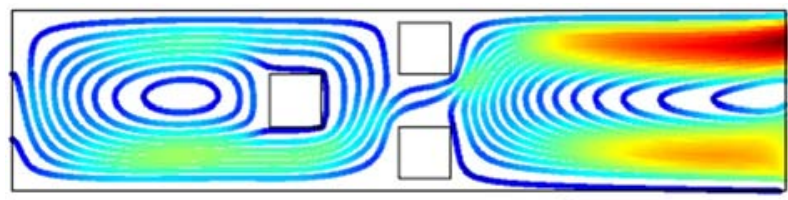

$H a=30$.

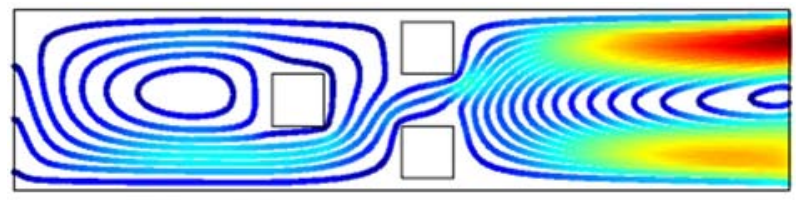

$H a=50$

Figure 6. Streamlines for $\mathrm{Ra}=10^{5}, \mathrm{Pr}=0.71 \mathrm{Ha}=0 ; \mathrm{Ha}=10 ; \mathrm{Ha}=30$.

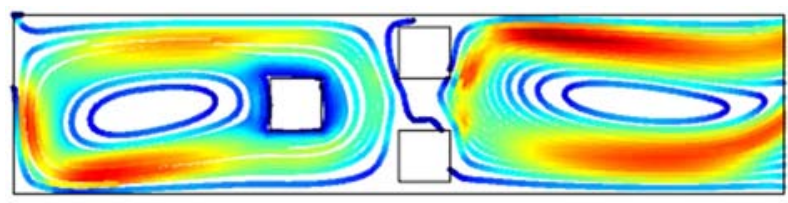

$H a=0$.

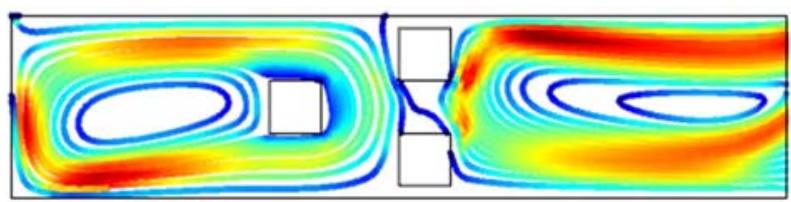

$H a=10$

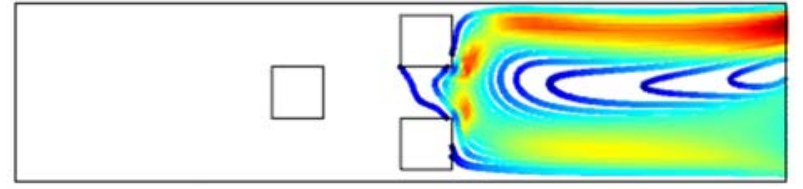

$H a=30$

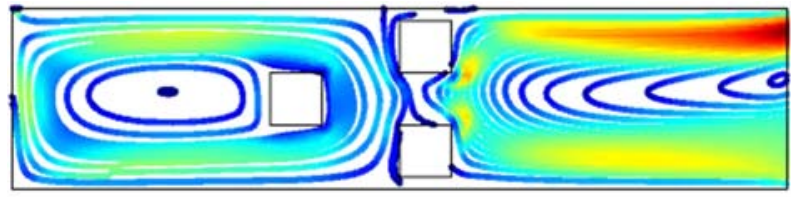

$H a=50$.

Figure 7. Streamlines for $\mathrm{Ra}=10^{6}, \mathrm{Pr}=0.71 \mathrm{Ha}=0 ; \mathrm{Ha}=10 ; \mathrm{Ha}=30 ; \mathrm{Ha}=50$.

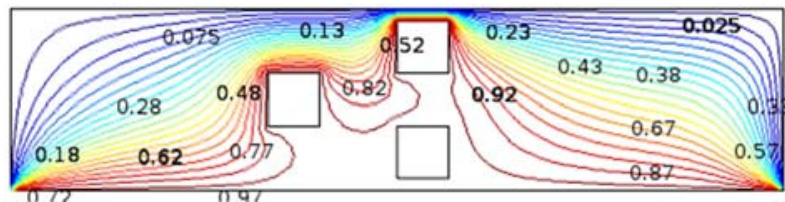

$H a=0$.

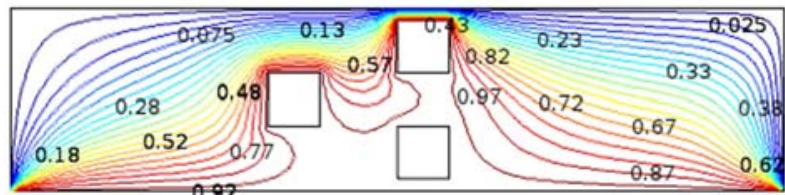

$H a=10$

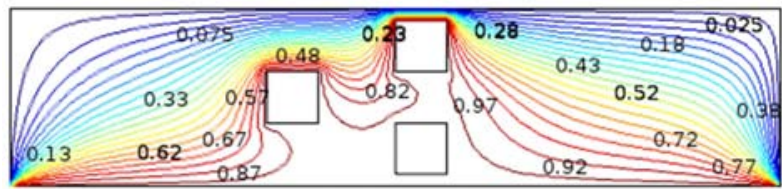

$H a=30$.

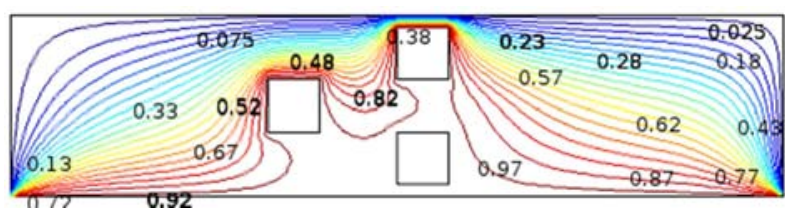

$H a=50$.

Figure 8. Isotherms for $\mathrm{Ra}=10^{3}, \mathrm{Pr}=0.71 \mathrm{Ha}=0 ; \mathrm{Ha}=10 ; \mathrm{Ha}=30 ; \mathrm{Ha}=50$.

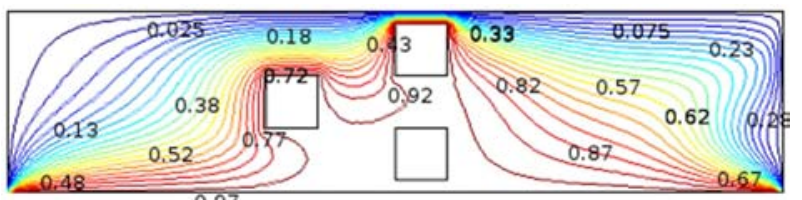

$\mathrm{Ha}=0$.

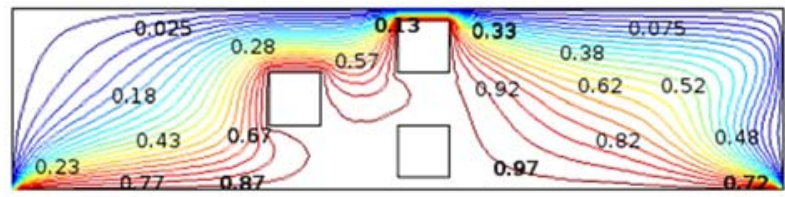

$H a=10$ 


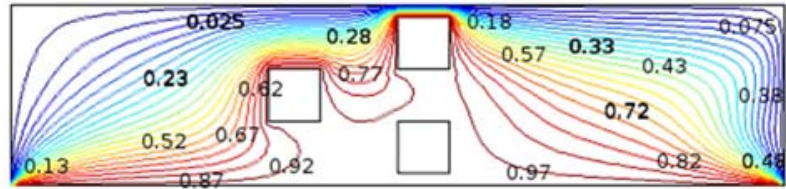

$\mathrm{Ha}=30$.

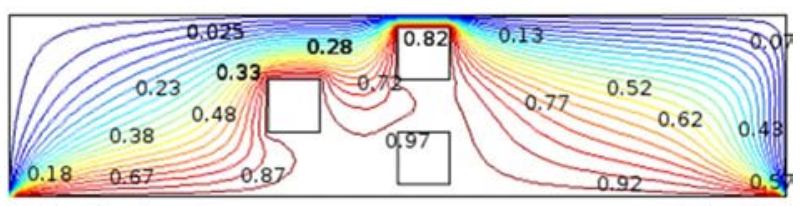

$H a=50$.

Figure 9. Isotherms for $\mathrm{Ra}=10^{4}, \mathrm{Pr}=0.71 \mathrm{Ha}=0 ; \mathrm{Ha}=10 ; \mathrm{Ha}=30 ; \mathrm{Ha}=50$.

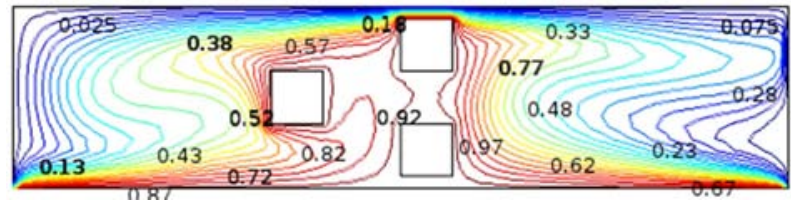

$\mathrm{Ha}=0$.

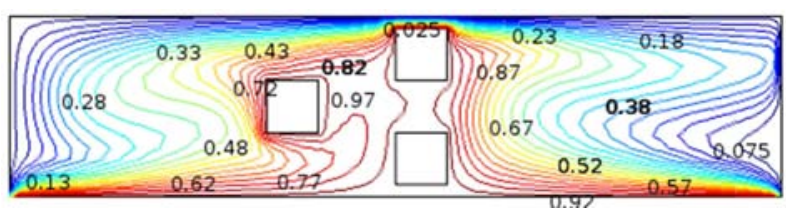

$H a=10$

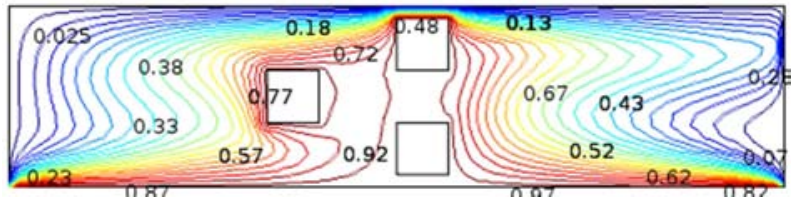

$H a=30$.

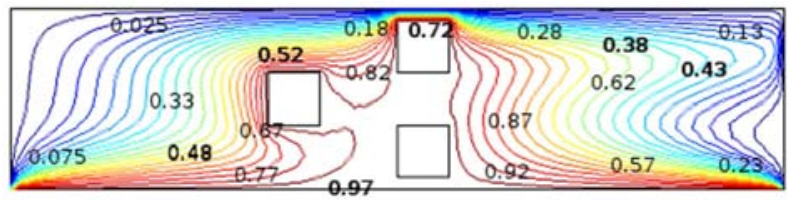

$H a=50$.

Figure 10. Isotherms for $\mathrm{Ra}=10^{5}, \mathrm{Pr}=0.71 \mathrm{Ha}=0 ; \mathrm{Ha}=10 ; \mathrm{Ha}=30 ; \mathrm{Ha}=50$.

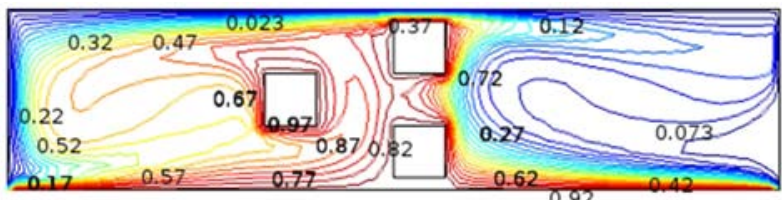

$\mathrm{Ha}=0$.

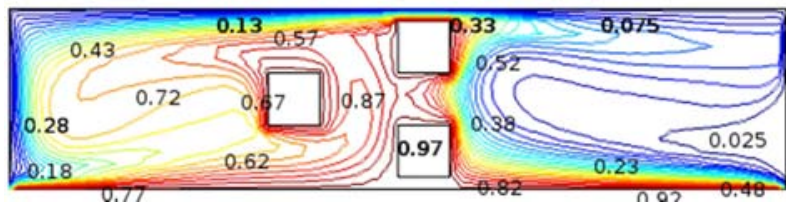

$H a=10$.

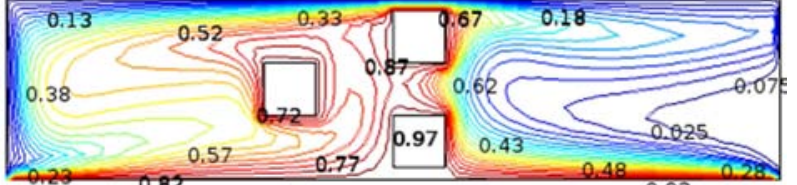

$H a=30$.

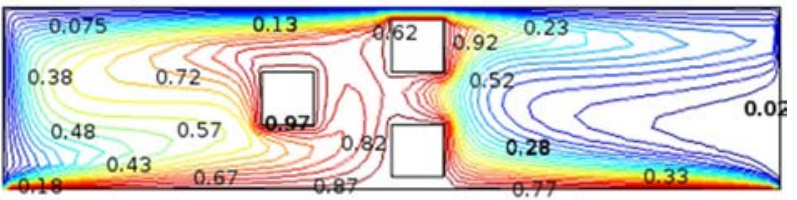

$H a=50$.

Figure 11. Isotherms for $\mathrm{Ra}=10^{6}, \mathrm{Pr}=0.71 \mathrm{Ha}=0 ; \mathrm{Ha}=10 ; \mathrm{Ha}=30 ; \mathrm{Ha}=50$.

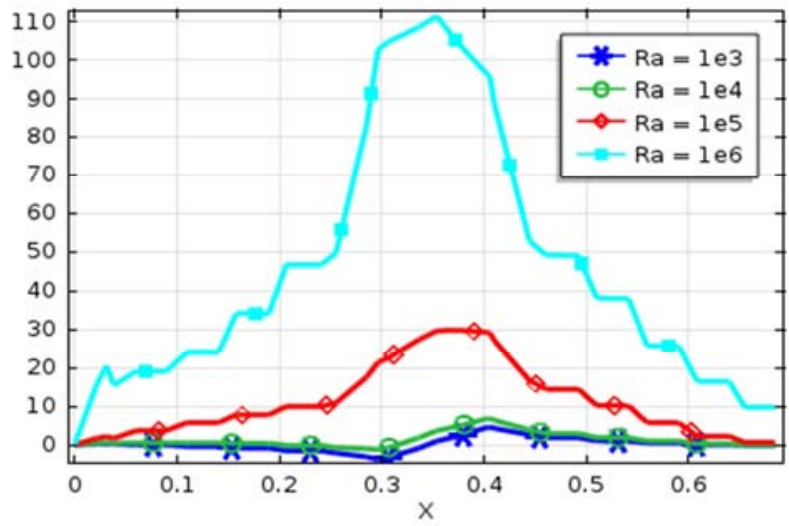

Figure 12. Variation of the vertical velocity components along the vertical centerline of the cavity with Rayleigh number for $\mathrm{Ha}=0$.

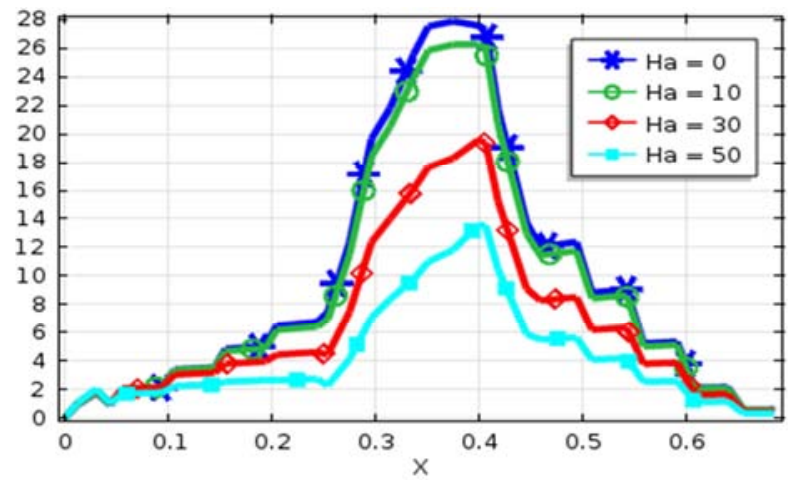

Figure 13. Variation of the vertical velocity components along the vertical centerline of the cavity with Hartmann number at $R a=10^{6}$.

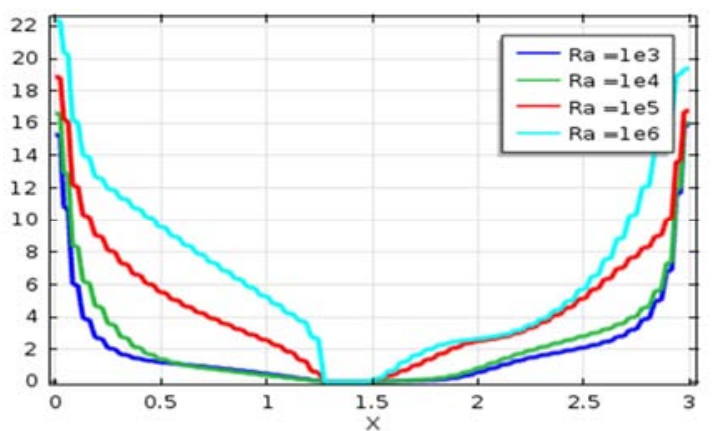

Figure 14. 1Variation of the local Nusselt number along the hot wall of cavity with Rayleigh number at $H a=0$. 


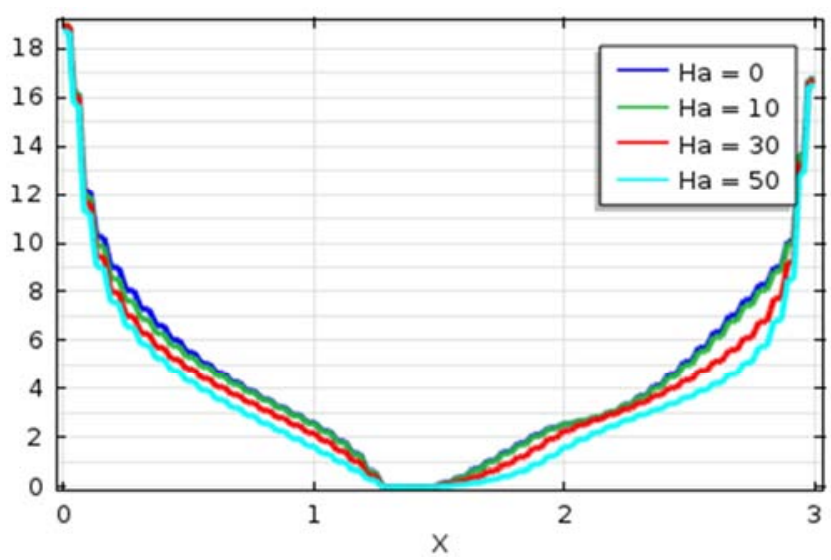

Figure 15. Variation of the local Nusselt number along the hot wall of cavity with Hartmann number at $R a=10^{6}$.

\section{Conclusion}

The study for the distribution of streamlines isotherms and local Nusselt number has been carried out to analysis the effect of dimensionless parameter. The investigation is considered the dimensionless parameter, Rayleigh numberPrandtl number and Hartmann number. The results have been presented for the chosen fluid of Prandtl number $\operatorname{Pr}=0.71$, Rayleigh number $\mathrm{Ra}\left(=10^{3}, 10^{4} 10^{5}\right.$ and $\left.10^{6}\right)$ and Hartmann number Ha $(=0,10,30$ and 50$)$. A computational study on natural convection in a rectangular cavity with three square shape heated block has been carried out. The governing equations of mass, momentum and energy equation were solved using finite element method. A few of findings are listed below:

1. The heat transfer mechanisms, temperature distribution and flow characteristics inside the enclosure depend upon magnetic field and Rayleigh number.

2. In absence of magnetic field the heat transfer rate is higher.

3. $\mathrm{Nu}$ increased for the increase of $\mathrm{Ra}$ number when $\mathrm{Ha}=0$.

4. $\mathrm{Nu}$ decreased for the increasing value of $\mathrm{Ha}$.

The obstructed body has significant effect to the flow and temperature field.

\section{References}

[1] M. K. Molallemi and K. S. Jang, "Prandtl number effects on laminar mixed convection heat transferin alid driven cavity", int. J. Heat and mass Tran. 35 pp, 1881-1892, 1992.

[2] Md. Shahidul Alam, M. A. Alim and Md. S. H. Mollah, "Mixed magneto convection in a lid driven square enclosure with a sinusoidal vertical wall and Joule heaing", procedia engineering 194 (2017) 463-470.

[3] A Malleswaran and S. Sivasankaran "A numerical simulation on MHD mixed convection in a lid drivencavity with corner heaters", Journal of applied fluid mechanic, Vol 09, no 1, pp 311-319, 2016.

[4] Ahmed F Khudheyer"MHD mixed convection in double lid driven differentially heated trapezoidal cavity “, int. Journal of application or innovation in engineering and management, Vol4, issue 2, February 2015.

[5] M. M. Rahman, M. A. Alim and M. M. A. Sarker"Numerical study on the conjugate effect of Joule heating and magneto hydrodynamics mixed convection in an obstructed lid driven square cavity In heat and mass transfer, 37 (2010), 524-534.

[6] M. K. Moallemi and k. S. Jang, "Prandtl number effects on laminar mixed convection heat transfer in a lid driven cavity", Int. J. Heat mass Transfer, Vol 35, No 8, pp 1881-1892, 1992.

[7] F. Hakan Oztop and Ihsan Dagtekin, "Mixed convection in two-sided lid -driven differentially heated square cavity", Int. J. of Heat and mass transfer, vol. 47, pp 1761-1769, 2004.

[8] S. Mahmud, and R. A. Fraser, "Magneto hydrodynamic free convection and entropy generation in a square porous cavity", Int. J. of Heat and mass Transfer (47), 3245-3256, 2004.

[9] S. Saha, G. saha and N. Hasan, "Mixed convection in a lid driven cavity with internal heat source", Procedings of the $13^{\text {th }}$ Annual paper meet 25 sep. 2011.

[10] S. Jani, M. Mahmoodi, and M. Amini, "Magneto hydrodynamic Free Convection in a Square Cavity Heated from Below and Cooled from Other Walls", International Journal of Mechanical and Mechatronics Engineering, Vol. 7, No. 4, 2013.

[11] M. S. Alam, M. S. H. Mollah, and M. A. Alim, "Finite Element Analysis of Natural Convection in a Rectangular Cavity and Partially Heated Wall", Engineering and Applied Sciences, Vol. 2, No. 3, pp. 53-58, 2017.

[12] M. S. Alam, M. S. Alam, M. A. Alim, and M. S. H. Mollah, "Numerical Simulation of Natural Convection in a Rectangular Cavity with Triangles of Different Orientation in Presence of Magnetic Field", AIP Conference Proceedings 1851, 020037 doi: 10.1063/1.4984666, 2017.

[13] M. S. Alam, M. S. H. Mollah, A. H. Bhuiyan and M. A. Alim, "Numerical Simulation of Natural Convection in a Rectangular Cavity with Corner Heater in Presence of Magnetic Field", Journal of Computer and Mathematical Sciences, Vol. 8, No. 6, pp 215-225, June 2017.

[14] M. S. Alam, M. S. Alam, M. S. H. Mollah, and M. A. Alim, "Effect of Prandtl Number on Magneto-Convection in a Lid Driven Square Cavity with a Sinusoidal Vertical Wall", Journal of Multidisciplinary Engineering Science Studies, Vol. 3 Issue 8, August-2017Journal of Multidisciplinary Engineering Science Studies, Vol. 3 Issue 8, 2017.

[15] M. S. Alam, M. S. Alam, M. A. Alim, and M. S. H. Mollah "Mixed Magneto Convection in a Lid Driven Square Enclosure with a Sinusoidal Vertical Wall and Joule Heating", Available online at www.sciencedirect.com1877-7058 (C) 2017 doi 10.1016/j.proeng.2017.08.172, 2017.

[16] A. B. Halim, M. A. Alim and M. U. Nasir "Effect of Hartmann Number on Free Convective Flow in a Square Cavity with Different Positions of Heated Square Block", World Academy of Science, Engineering and Technology International Journal of Mathematical, Computational, Physical, Electrical and Computer Engineering Vol. 8, No: 2, 2014.

[17] J. Abraham and J. Varghese, "Mixed convection in a differentially heated square cavity with moving lids", Int. J. of engineering Research \& Technol. (IJERT) ISSN-2278-0181, no, 1-4, issue 12, 2015. 
[18] P. M. kishore, V. Rajesh, S. V. K. Verma, "Effects of heat transfer and viscous dissipation on MHD free convection flow past an exponentially accelerated vertical plate with variable temperature", Journal of naval Architecture and Marine Engineering Vol. 7, No. 2, pp 101-110, 2010.

[19] A. K. M. Sadrul Islam, M. Z. Hossain, M. A. H. Mamun, andS. Shaha "Mixed convection in an enclosure with different inlet and exit configuration", Journal of Applied Fluid Mechanics, vol 1, no 1, pp 78-93, 2008.

[20] A. Raji and M. Hasnaoui, "Mixed convection heat transfer in a rectangular cavity ventilated and heated from the side", An international journal of computation and methodology 33: 5,533-548 (1998).

[21] N. G. Carona, M. Corcione and E. Habib, "Natural convection in shallow and tall cavity with the four walls differentially heated", $6^{\text {th }}$ international conference on heat transfer, Fluid mechanics and thermodynamics 30 June 2008.

[22] M. Ghalambaz, M. Sabour and I. Pop, "Free convection in a square cavity filled by a porous medium saturated by a nanofluid: Viscous and radiation effects", Engineering science and technology, an international journal-2016.

[23] E. C. Mehmetand Eliif Buyuk, "Natural convection flow under a magnetic field in an inclined rectangular enclosure heated and cooled on adjacent walls", Fluid dynamics research 38 (2006), 564-590.

[24] B. Paritosh and D. songita, "A numerical study of laminar natural convection heat transfer inside a closed cavity with different aspect ratio", U. P. B Sci-Bull series-1, Vol 77, Issue 2,2015 .

[25] A. Gowriskankar, S. Vignesh, P. B. ShyamSunder, R. Abhinav, M. Vivek and V. RatnaKishon, "Numerical study of natural convection in an enclosure with an internal heat source at higher Rayleigh number" Heat transfer Asian Research, 44 (7), 2015.

[26] S. Roy and tonmoyBasak, "Finite element analysis of natural convection flows in a square cavity with non-uniformly heated wall(s)", Int. J. of engineering Science, 43, (2005), 668-680.

[27] Khalil M. Khanafer, Ali J. Chamka, "Mixed convection flow in a lid driven enclose filled with a fluid-saturated porous media", Int. J. Heat and mass Transfer, 42, (1999)2481.

[28] C. Taylorand V. Hood, "A numerical solution of the NavierStokes equations using finite element techniqueComput. Fluids, 1, pp. 73-89 (1973). 